\title{
CHARACTERIZATION AND PERFORMANCE OF ELEMENTARY HEMP FIBRES: FACTORS INFLUENCING TENSILE STRENGTH
}

\author{
Mizi Fan ${ }^{\text {a }}$
}

\begin{abstract}
This paper presents the outcomes from an extensive investigation on the structure and geometry of single hemp fibres, as well as configurations and related tensile strength (TS) of hemp fibres, with the aid of field emission scanning and optical microscopy. The results showed that 1) the TS increased with the decrease of the diameter of individual test pieces, due possibly to the stacks of multiple single fibres within the test pieces; 2) shear failure between single fibres in a test pieces played a significant role in the test results; 3 ) the TS was closely related to the number of both the inherent joints along the fibre length and single fibres contained in the test pieces; 4) the splits along the length and width of hemp fibres may complicate the test results, and 5) the optimized treatment prior to decortications may double the TS of hemp fibres compared to a normal retting processing. Reliable TS of single hemp fibres have been derived by a power regression, and the predicted TS were verified with an excellent agreement with experimentally tested results. The tensile strain-stress plot was found to be linear for all hemp test pieces, showing that the behaviour of single hemp fibres obeys Hooke's law.
\end{abstract}

Keywords: Tensile strength; Single elementary hemp fibre; Prediction; Inherent and processing defects; Configuration

Contact information: a: Director, Nano Cellulose and Composites Research Centre (NRC), Head of Research, Department of Civil Engineering, Brunel University, UB8 3PH, UK. Email:

mizi.fan@brunel.ac.uk

\section{INTRODUCTION}

Hemp fibre has been considered to be one of the most important types of natural bast fibres for industrial applications (Panthapulakkal 2007). It has been widely used in many civilizations for over 6000 years (Roulac 1997; Beckermann 2007; Stafford 1994) for such purposes as the fabrication of ropes, paper, and textiles. Hemp fibres have long been valued for their high strength and long fibre length. Environmentally, hemp fibres perform better than glass by weight with respect to the life cycle analysis (LCA) from cradle to manufacture (Anderson et al. 2004). In some cases the specific properties of the hemp fibres were found to be better than those of glass fibre (Table 1) (Wambua et al. 2003). Comparative studies of natural fibre and glass fibre composites concluded that natural fibres could replace glass fibres for composites that did not require high load bearing capabilities (Wambua et al. 2003). 
Table 1. Specific Properties of Plant Fibre Compared to Synthetic Fibre

\begin{tabular}{cccc}
\hline Fibre & $\begin{array}{c}\text { Specific gravity } \\
\left(\mathrm{kg} / \mathrm{cm}^{3}\right)\end{array}$ & Specific TS (GPa) & Specific E (T) (GPa) \\
\hline Plant & $800(600-1200)$ & $2.31(1.6-3.0)$ & $65(10-130)$ \\
\hline Glass & 2600 & 1.35 & 30 \\
\hline Kevlar & 1400 & 2.71 & 90 \\
\hline Carbon & 1800 & 1.71 & 130 \\
\hline
\end{tabular}

Hemp fibres consist of different hierarchical microstructures (Fan et al. 2010), whereby microfibrils serve as basic units. The microfibrils are embedded in a matrix of hemicelluloses and/or lignin, and they form the different cell wall layers of an elementary fibre, which generally has a large average diameter ranging from 10 to $50 \mu \mathrm{m}$ (Candilo et al. 2000). The elementary fibres are bonded together with pectins and small amounts of lignin framing the next level of microstructure, i.e. technical fibres, with a diameters ranging from 50 to $100 \mu \mathrm{m}$ (Bhuwan et al. 2003). These technical fibres (filaments) are fixed together with a pectin-lignin matrix to form fibre bundles in the cortex of plant stems (i.e. bast fibres). The microfibrils run roughly parallel to each other, following a steep helix around the cell (Purz et al. 1998; Hearle 1963; Bos and Donald 1999), and are composed of crystalline and amorphous regions alternately. The microfibrils contain a large quantity of cellulose molecules. Cellulose has outstanding properties at the crystal level. It has been reported that the crystal modulus of cellulose I may be as high as 138 GPa, cellulose II 88 GPa, cellulose III 73 GPa, and cellulose IV 75 GPa (Nishino 2004). Hemp fibres and other plant fibres including wood fibres mainly contain cellulose I.

Numerous research projects have been carried out on natural fibres and their composites, e.g. sisal fires by Mwaikambo et al. (2006), wood pulp by Bos and Donald (1999), cotton by Thygesen et al. (2006), and flax by Hamad and Eichhorn (1997). A comprehensive review has also been published by Eichhorn et al. (2001). However, it is evident that the published data is highly variable from one worker to another (Table 2) (Satyanarayana et al. 2009). The experience has highlighted that it is inappropriate to use or compare data available from different investigations reported in the literature. While some inherent factors (e.g. cultivation conditions, harvesting season, and geographical difference) may have contributed to the observed variations, assessing natural fibres has proven to be most challenging. Microstructural defects, fibre abstraction (e.g. how to obtain a single fibre), processing, and measurements are all yet to be further improved despite some work has been carried out by previous researchers. For example, Thygesen et al. (2006) compared different visualisation effects of dislocations in hemp fibres between scanning electron microscopy (SEM) and polarized light microscopy. Hu et al. (2010) tried to improve the standard deviation of the tensile strength of flax fibres by using Scanning Electron Microscope observation of a flat and clear fractured end surface of fibres, making use of image analysis. Davies and Bruce (1998) studied the effects of environmental conditions and mechanical damage on the tensile stiffness and strength of flax and nettle fibr, and concluded that there was a consistent relationship between modulus and relative humidity. Xue et al. (2009) evaluated the effect of temperature and loading rate on the tensile properties of kenaf and its epoxy strand and concluded that the 
elastic modulus, tensile strength, as well as failure strains of kenaf fibre and its epoxy strand varied considerably, ranging from $10 \%$ to $30 \%$. The strength of composites made from commercial hemp fibres is also found to be much lower than that from the single hemp fibre or the theoretically calculated strength of the composite of hemp and polyester in accordance with the rule of mixtures (Fig. 1) (Fan 2009), which leads to the question of whether the hemp fibres within a composite transfer/convey the stress. If yes, the performance data of hemp fibres used may not be reliable and/or repeatable. This paper is one of a series of papers aimed at answering these questions. The paper examines the main factors affecting the tensile strength and other tested results. The paper then demonstrates cases where reliable and repeatable tensile strength of elementary hemp fibres were achieved.

Table 2. Properties of Various Fibres

\begin{tabular}{ccccc}
\hline Fibre & Density $\left(\mathrm{kg} / \mathrm{cm}^{3}\right)$ & EL $(\%)$ & TS $(\%)$ & E (GPa) \\
\hline Hemp & 1500 & 1.6 & $310-850$ & - \\
\hline Flax & 1500 & $2.7-3.2$ & $345-1035$ & $60-80$ \\
\hline Jute & 1500 & $1.5-1.8$ & $400-800$ & $10-30$ \\
\hline Sisal & 1500 & $2.0-2.5$ & $511-635$ & $9.4-22.0$ \\
\hline Cotton & 1500 & $7.0-8.0$ & $287-597$ & $5.5-12.6$ \\
\hline Softwood & 1500 & - & 1000 & 40 \\
\hline E-glass & 2500 & 2.5 & $2000-3500$ & 70 \\
\hline Carbon & 1400 & $1.4-1.8$ & 4000 & $230-240$ \\
\hline
\end{tabular}

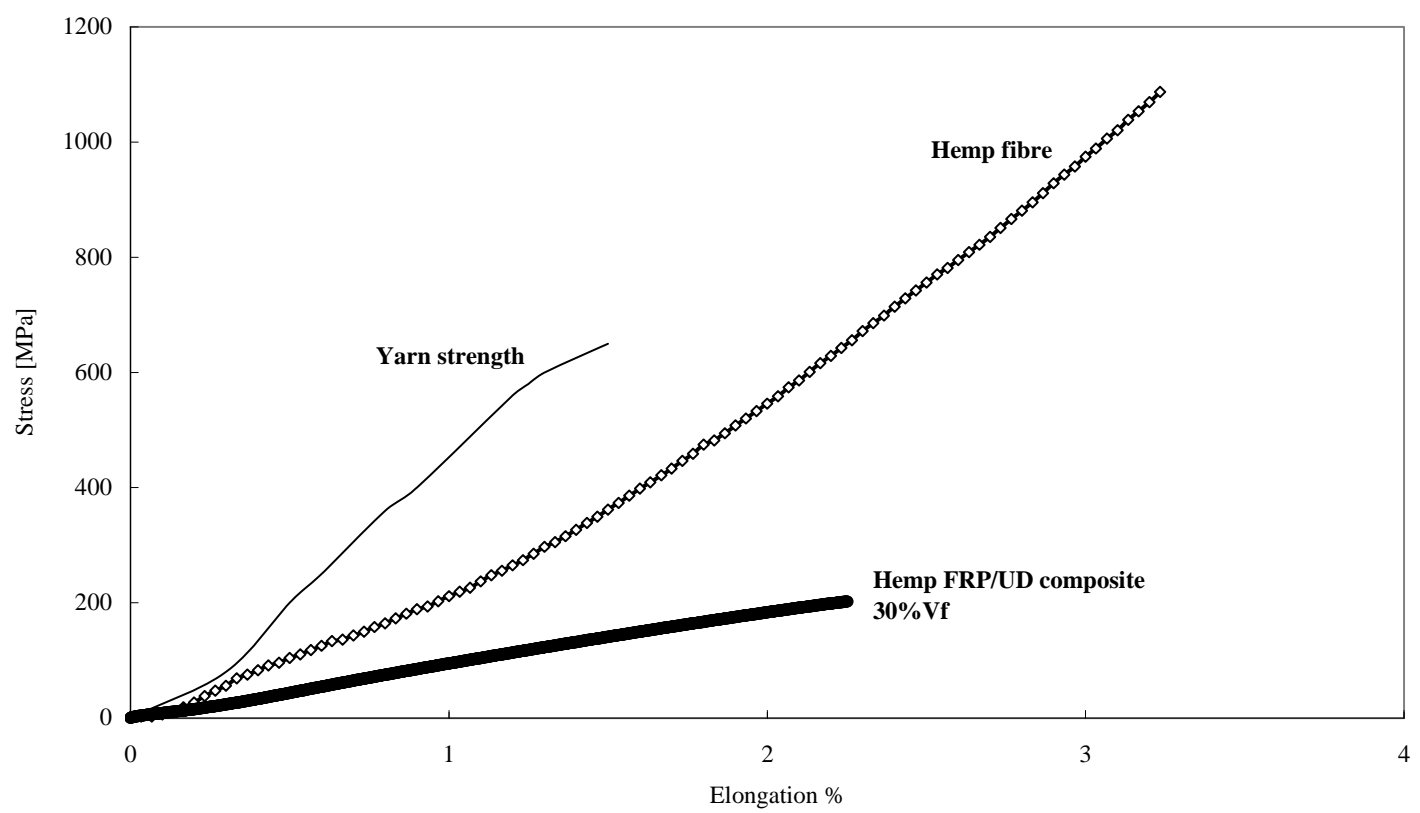

Figure 1. Stress vs. elongation for hemp fibre, hemp yarn, and hemp fibre composite 


\section{MATERIALS AND METHODS}

\section{Material Preparation}

Hemp fibres were processed and supplied by a UK commercial company 'Hemp Farm and Fibre Ltd'. The fibres arrived in the form of bast fibre bundles. A handful of the fibre bundles from each type of material were randomly sampled from the received materials and soaked in distilled water for 24 hours under a normal indoor environment ( $20^{\circ} \mathrm{C} / 60 \%$ relative humidity). The samples, either single fibre or fibre bundle, were randomly and gently isolated from the wetted hemp bast fibre bundles. All isolated fibres were re-conditioned at $20^{\circ} \mathrm{C}$ and $65 \%$ relative humidity before use.

\section{Observation and Diameter Measurement}

Optical microscopy was employed to examine the geometry and surface defects of hemp fibres. The BX51 Reflected Light Microscope is equipped with $5 \times$, 20×, 50×, $100 \times$ objectives, a CAM-XC50 - 5MP cooled CCD camera and a 100W Halogen for transmitted or reflected light. For the surface examination, the fibres were positioned on a slide using cyanacrylate glue and covered with a cover slip. Images were analysed and captured as $2576 \times 1932$ RGB jpeg files. Various defects (defects in this study mean that there is a dislocation (flaw) or fibre diameter/breadth is smaller or a combination of both) were then recorded and analysed. The breadth of individual test pieces was measured. The experiments were performed at room temperature, and 1000 test pieces were examined.

\section{Tensile Test}

The observed fibres were then temporarily fixed on the mounting card (Fig. 2) with adhesive tape. A droplet of glue was applied on the centre of both sides of the hole along the length of the card. The testing was then carried out as follows:

1) The prepared samples were again subjected to optical microscopy to examine an accurate diameter of the test pieces. The diameter was this time measured in three positions (Fig. 2C), and the mean values were used for data processing;

2) The samples were evaluated with an electromechanical tensile machine with mechanical grips (clamp both ends of the sample card);

3) Both sides of the card were cut in the middle;

4) The test pieces were tested at a crosshead speed of $0.1 \mathrm{~mm} / \mathrm{min}$ and with $25 \mathrm{~mm}$ gauge length;

5) The strain and stress of the loaded test pieces were tested automatically with Instron software.

The fracture surface of the broken test pieces was re-examined with the optical microscopy for evaluation of failure modes. 

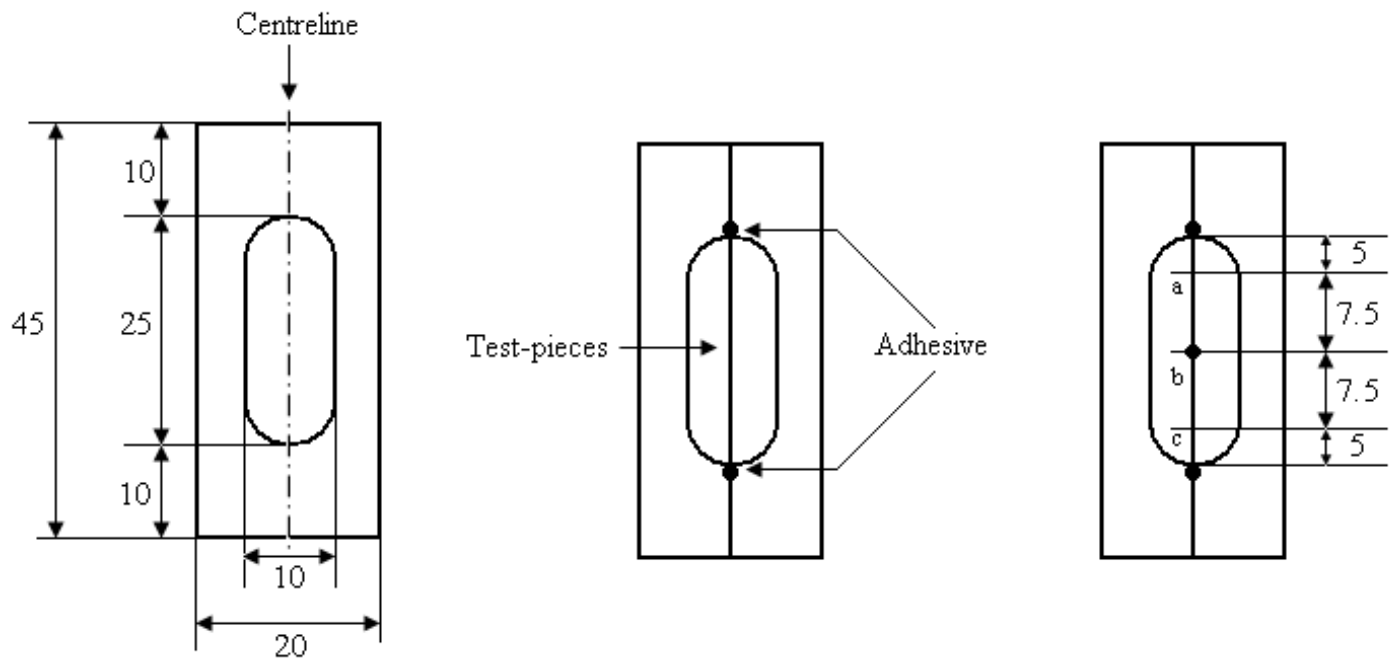

Figure 2. Test set-up: $A=$ dimension of card (in $\mathrm{mm}$ ), $B=$ fixing of test pieces, $C=$ measuring points for diameter

\section{RESULTS AND DISCUSSION}

\section{Configuration of Test Pieces and its Effect on Test Data}

It was found that the sampling processes and sample geometry had significant effects on the tested results for hemp fibres. The tested results for a set of 10 different types of hemp fibres are given in Table 3 . In line with the literature, there was a huge range of the observed tensile strength between the lowest and highest strength of individual test pieces: the ratios of the highest to lowest tensile strength tested for these hemp fibres were $24,9,11,12,12,5,11,11,8$, and 21 for the eight types of hemp fibres, respectively. The questions to be answered are why there is so significant variation between the test pieces and which value represents a real strength of a single hemp fibre.

A scrutiny of one set of the data shows that the tensile strength was closely related to the diameter of the pieces tested (Fig. 3), i.e. the specific strength increased as the diameter of individual test pieces decreased, indicating that either the samples having larger diameter contained more defect/weak points or the test pieces may contain several single fibres. The effect of the former on the test strength will be discussed in more detail in later sections.

Observations of the breaking processes and fracture surfaces supported the hypothesis that many of the test pieces contained several single fibres. An example of failure modes of the test pieces before, during, and after tensile testing is illustrated in Fig. 4. Figure 4A shows a gradual increase in diameter of the test pieces from the unaffected area to the fracture point under tensile stress rather than a decrease, in accordance with the Poisson effect. The increase in diameter implicates the loosening of the structure, which mainly happens between single fibres within the test pieces (fibre bundles). This is indeed verified from the fracture mode of test pieces after the tensile test (Fig. 4B), showing a split between at least two single fibres. 
Table 3. Overall Range of Tensile Strength (MPa) of Hemp Test Pieces*

\begin{tabular}{lrrrrrrrrrr}
\hline ID & SCS1 & SCS2 & SCS3 & SCS4 & SCS5 & SCS6 & SCS7 & SCS8 & GN04 & GN05 \\
\hline 1 & 27.3 & 37.1 & 43.6 & 45.8 & 61.1 & 62.1 & 65.4 & 69.8 & 56.7 & 50.1 \\
\hline 2 & 63.2 & 48.0 & 45.8 & 82.9 & 82.9 & 65.4 & 98.1 & 89.9 & 63.2 & 69.8 \\
\hline 3 & 67.6 & 56.7 & 48.0 & 93.8 & 93.8 & 85.0 & 100.3 & 91.6 & 63.2 & 94.8 \\
\hline 4 & 74.1 & 78.5 & 67.6 & 98.1 & 100.3 & 87.2 & 109.0 & 103.6 & 80.7 & 98.1 \\
\hline 5 & 85.0 & 87.2 & 67.6 & 98.1 & 109.0 & 89.4 & 148.3 & 154.8 & 100.3 & 117.7 \\
\hline 6 & 100.3 & 87.2 & 89.4 & 137.4 & 114.5 & 89.4 & 157.0 & 185.3 & 100.3 & 130.8 \\
\hline 7 & 128.6 & 89.4 & 109.0 & 182.1 & 133.0 & 91.6 & 169.0 & 248.6 & 104.7 & 135.2 \\
\hline 8 & 135.2 & 106.8 & 126.5 & 215.9 & 133.0 & 98.1 & 174.4 & 255.1 & 117.7 & 135.2 \\
\hline 9 & 137.4 & 113.4 & 161.3 & 228.9 & 148.3 & 104.7 & 211.5 & 292.2 & 119.9 & 152.6 \\
\hline 10 & 143.9 & 115.6 & 170.1 & 235.5 & 185.3 & 106.8 & 218.0 & 303.1 & 119.9 & 176.6 \\
\hline 11 & 146.1 & 133.0 & 187.5 & 242.0 & 187.5 & 124.3 & 257.3 & 308.6 & 124.3 & 183.2 \\
\hline 12 & 155.9 & 146.1 & 200.6 & 265.5 & 261.6 & 140.8 & 267.3 & 328.8 & 137.4 & 195.1 \\
\hline 13 & 174.4 & 148.2 & 209.3 & 274.5 & 262.8 & 150.4 & 287.5 & 340.1 & 139.5 & 224.6 \\
\hline 14 & 180.2 & 154.9 & 244.2 & 280.2 & 294.4 & 157.0 & 290.0 & 341.2 & 163.5 & 266.0 \\
\hline 15 & 189.8 & 157.0 & 285.6 & 298.7 & 351.0 & 158.4 & 294.4 & 361.9 & 165.7 & 293.3 \\
\hline 16 & 235.5 & 209.3 & 285.6 & 344.5 & 353.2 & 165.7 & 370.7 & 368.5 & 172.6 & 309.6 \\
\hline 17 & 250.7 & 224.6 & 331.4 & 375.0 & 361.9 & 179.9 & 385.9 & 428.4 & 251.8 & 339.1 \\
\hline 18 & 274.7 & 230.0 & 333.6 & 381.6 & 436.1 & 198.4 & 444.8 & 431.7 & 268.2 & 348.9 \\
\hline 19 & 303.1 & 248.6 & 353.2 & 462.2 & 441.5 & 215.9 & 477.5 & 490.6 & 287.8 & 418.6 \\
\hline 20 & 307.4 & 252.9 & 370.7 & 508.0 & 468.8 & 266.0 & 536.4 & 534.2 & 309.6 & 532.0 \\
\hline 21 & 324.9 & 271.5 & 412.1 & 545.1 & 494.9 & 324.9 & 586.5 & 545.1 & 390.3 & 536.4 \\
\hline 22 & 560.4 & 335.8 & 475.3 & 545.1 & 702.1 & 333.6 & 708.6 & 737.0 & 455.7 & 1040.0 \\
\hline Av & 184.8 & 151.4 & 209.9 & 270.0 & 262.6 & 149.8 & 277.3 & 318.6 & 172.4 & 265.8 \\
\hline Cov & 68 & 56 & 62 & 59 & 66 & 55 & 65 & 56 & 65 & 86 \\
(\%) & & & & & & & & & & \\
\hline & & & & & & & & & &
\end{tabular}

* SCS1 SCS8, GN04 and GN05 =names denoted to different sampling processes.

* Cov=coefficient of variation.

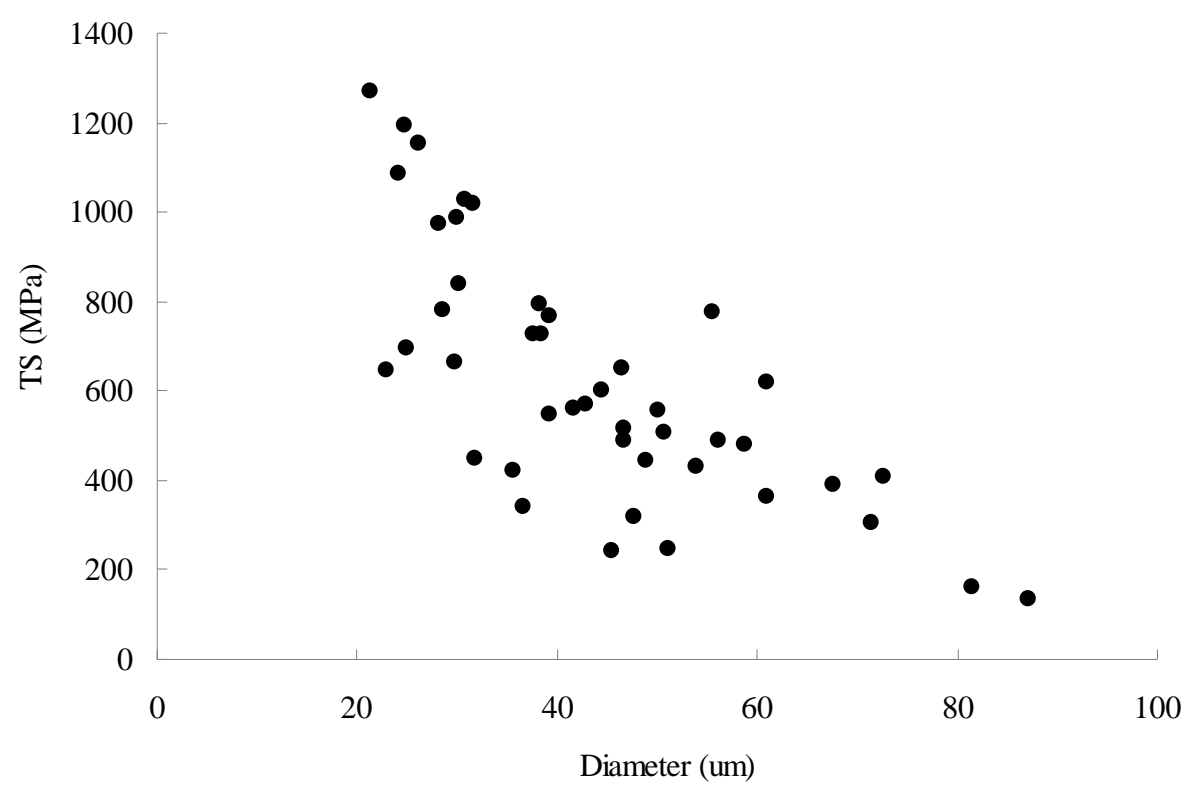

Figure 3. TS versus diameter of test pieces 

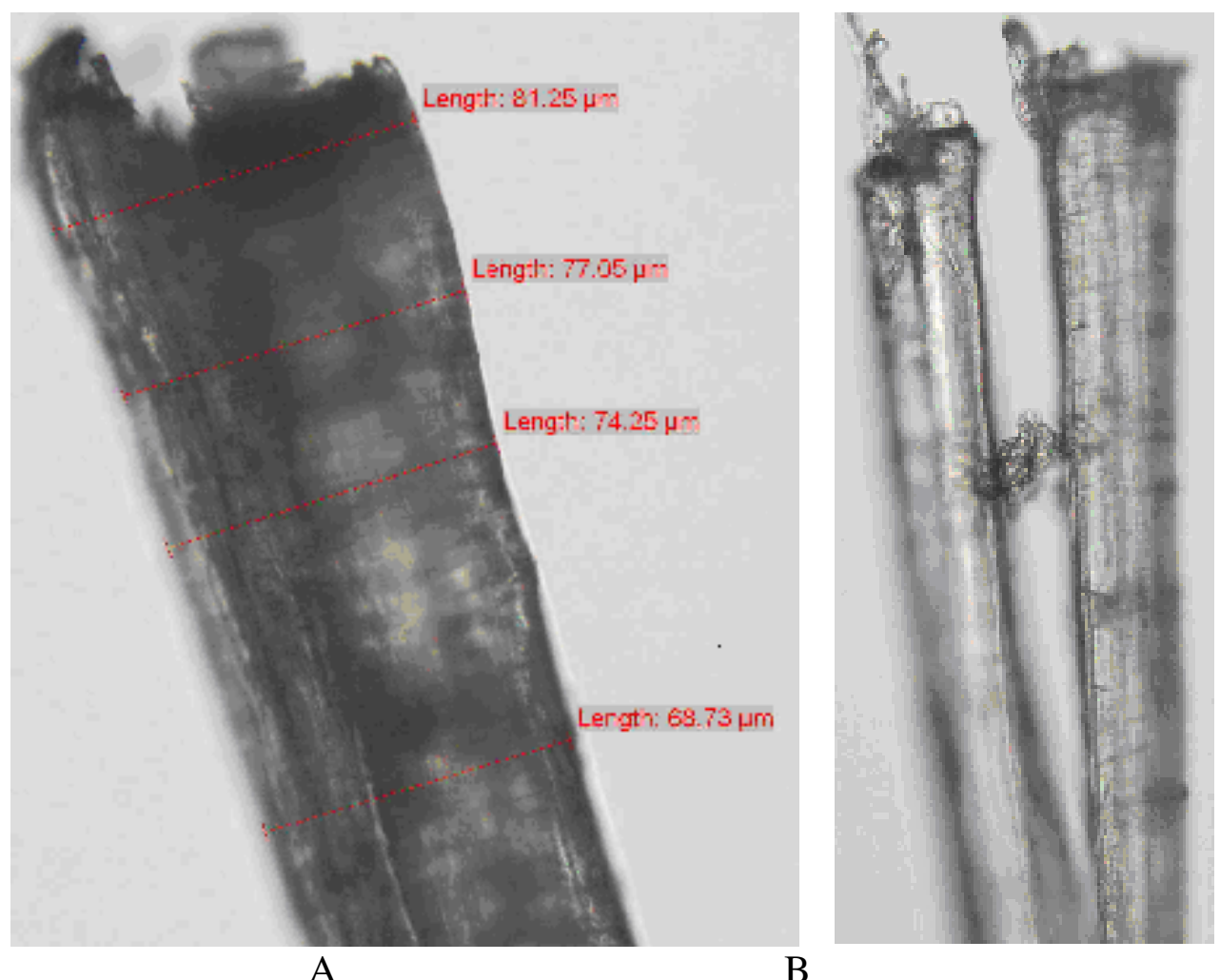

B

Figure 4. Failure modes: $A=$ diameter increases from unaffected region to fracture surface, $B=$ split near the fracture surface after tensile testing

A SEM examination of hemp fibres provided further verification of the above observation. Figure 5 shows that the diameter (breadth) of single hemp fibres mostly ranged from 10 to $15 \mu \mathrm{m}$. By contrast, the diameter (breadth) of the test pieces examined mostly ranged from 20 to $60 \mu \mathrm{m}$, indicating that each test pieces was likely to have contained more than 2 single fibres or more.

Data analysis of the diameter measured in three positions of test pieces, i.e. left (L), middle (M), and right (R) (Fig. 2C) also indicated that the test pieces may contain several single fibres. The plot for one set of the test data (as an example) is given in Fig. 6. In the figure each curve links the tested value of the diameters of positions left, middle, and right. It is apparent that the difference between the three positions was very significant. The highest difference between three positions of a test pieces was $37.5 \mu \mathrm{m}$, which could be four times the diameter of a single hemp fibre. The average difference for this set of the test pieces was about $15 \mu \mathrm{m}$.

Evaluation of test pieces containing multi-fibres may result in a significant variation of test results. The tested value obtained could be the pure tensile strength, the pure shear strength between short fibres, or a mixture of shear and tensile strength. Figure 7 gives an example of the possible combinations of a test pieces, showing a possible contribution of shear strength to the overall tested value, that is $0,30,0,60,100 \%$ from left to right, based on the configurations shown, respectively. 


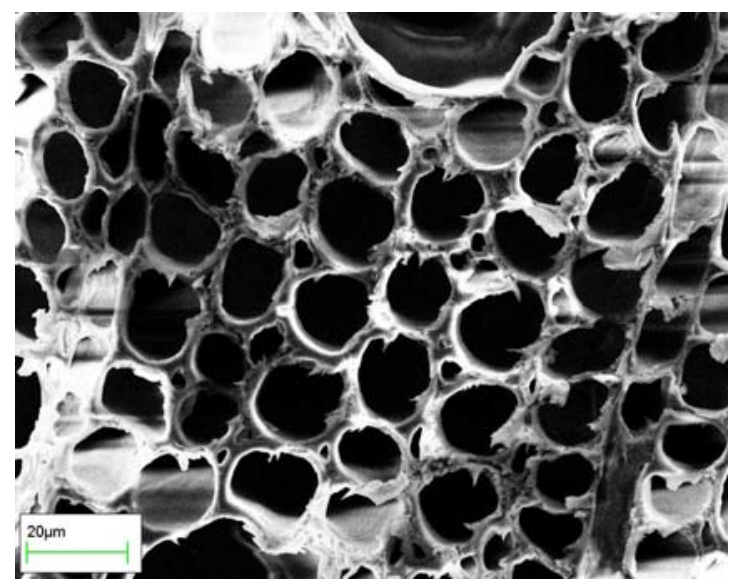

Figure 5. Cross section of hemp bast fibre

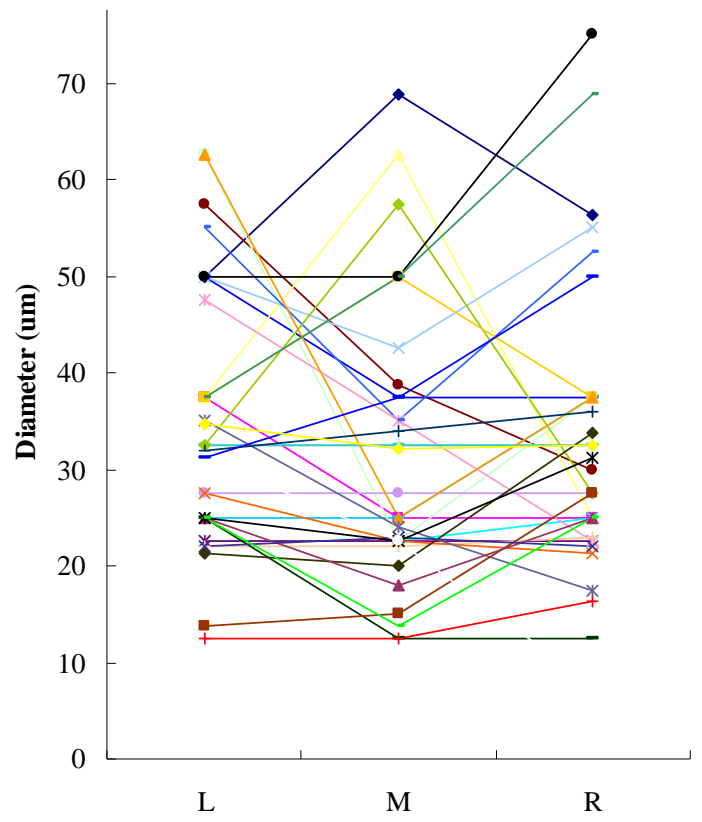

Figure 6. Diameter along the length of test pieces

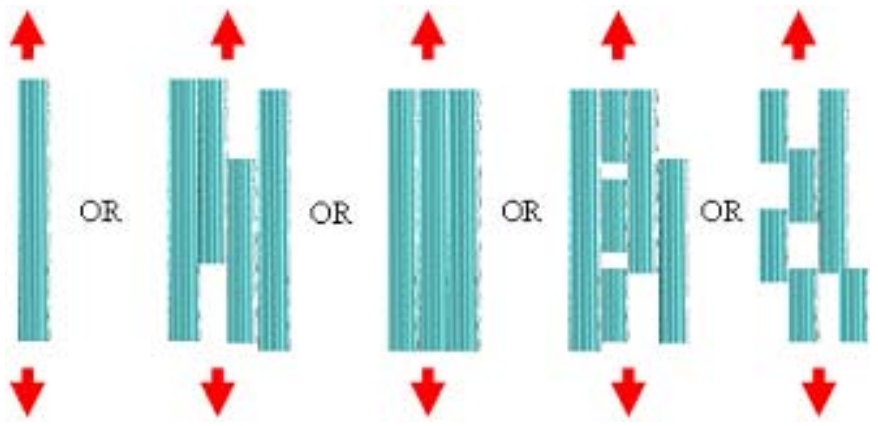

Figure 7. Possible configurations of single fibres in a test pieces

\section{Prediction of Reliable (real) Tensile Strength of Single Hemp Fibres}

Figure 8 shows the tested data from the test pieces containing various diameters, fibres from various plants, and fibres from various positions of a plant; i.e. the test pieces were randomly sampled from commercial hemp fibres. While the strength increased as the fibre diameters decreased, a power regression line could be used to predict the correlation with a high degree of fit to the data $\left(\mathrm{R}^{2}=0.88\right)$. Therefore, the relation between the strength and diameter of test pieces can be written as:

$$
T S=44805 D^{-1.2093}
$$




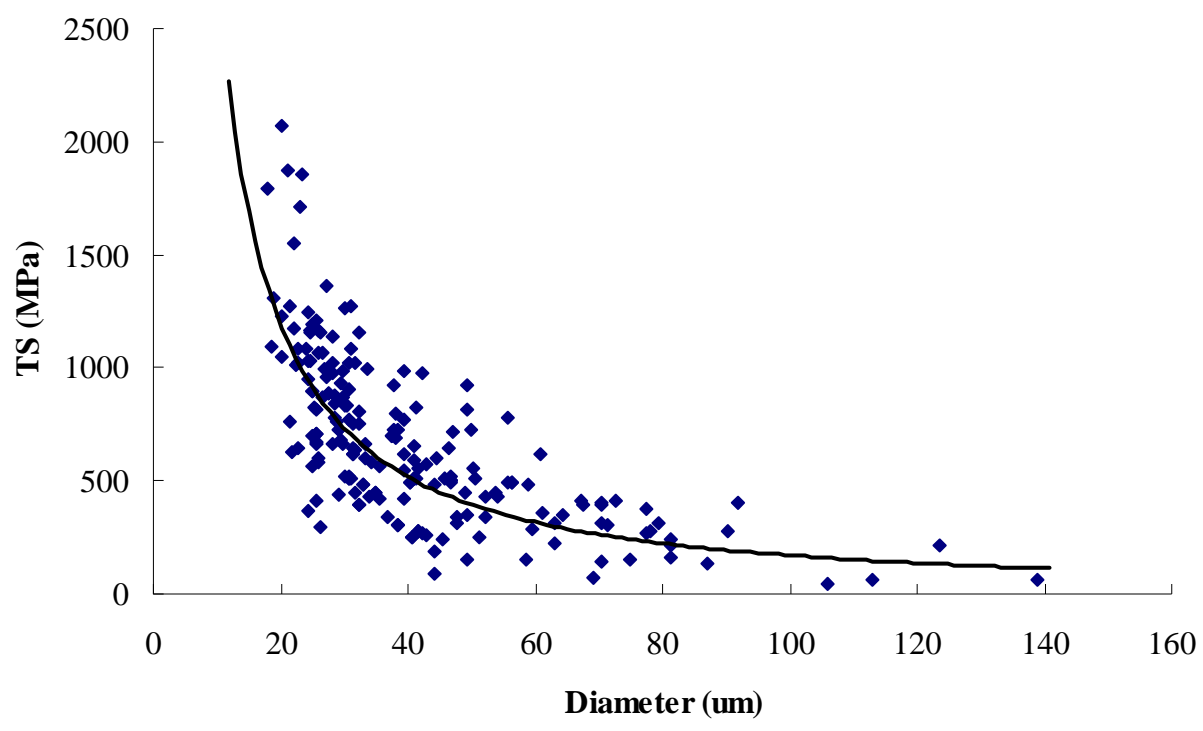

Figure 8. Tested and predicted tensile strength of hemp fibres

As mentioned earlier, the diameter of single hemp fibres tested in this study should be in a range of 10 to $15 \mu \mathrm{m}$. Therefore, the strength of a single hemp fibre should be in a range of $1695 \mathrm{MPa}$ (using $15 \mu \mathrm{m}$ diameter) to $2767 \mathrm{MPa}$ (using $10 \mu \mathrm{m}$ diameter). If the diameters of 20 and $25 \mu \mathrm{m}$ are used, then the strength is $1197 \mathrm{MPa}$ for the former and $914 \mathrm{MPa}$ for the latter, respectively.

\section{Verification Test of Tensile Strength}

The tensile strength predicted from the power equation 1 was further verified. The isolation/sampling of test pieces was carried out by an aid of optical microscopy; i.e. each test piece was carefully prepared and examined under an optical microscope to ensure its accurate diameter. A set of 20 well-prepared test pieces were tested, and the results are given in Table 4. It can be seen that the average tensile strength of test pieces with a diameter $<30 \mu \mathrm{m}$ was $1256 \mathrm{MPa}$, and that with a diameter between 30 and $50 \mu \mathrm{m}$ was 529 MPa. The COV for the former group was 20\% and for the latter group 23\%.

The correlation of strain and stress for these carefully prepared hemp test pieces was also plotted. It is evident that the strain-stress of single hemp fibres showed a linear correlation for all the test pieces. An example of the plots is given in Fig. 9. It must be noted that for most of test pieces the first small portion of the stress-strain curve seemed to be nonlinear (Fig. 9A). However, a scrutiny of the curve shows that this was due to a fluctuation of some testing data (the data points 2-9) occurring in that part (Fig. 9B). The higher stress (data points) was due probably to the deposition of other residues (e.g. chemicals, etc. during retting or treatments) on the fibre tested, because these residues may work as 'reinforcement' for the fibre. The residues may also restrain the normal stretch of the fibre. As soon as they (the residues) failed, the test pieces behaved in a linear manner and the behaviour of single hemp fibres obeyed Hooke's law. This is also in agreement with a study on flax fibre carried out by Charlet et al. (2009), who proposed a progressive alignment of the cellulose microfibrils with the tensile axis. 
Table 4. Tensile Strength of Well-Prepared Test Pieces

\begin{tabular}{ccc|ccc}
\hline Sample ID & $\mathrm{D}(\mu \mathrm{m})$ & $\mathrm{TS}(\mathrm{MPa})$ & Sample ID & $\mathrm{D}(\mu \mathrm{m})$ & TS $(\mathrm{MPa})$ \\
\hline & $\mathrm{D}=30-50 \mu \mathrm{m}$ & & & $\mathrm{D}<30 \mu \mathrm{m}$ & \\
\hline $8-1$ & 34.0 & 430 & $8-2$ & 22.1 & 1553 \\
\hline $8-3$ & 41.0 & 593 & $8-4$ & 26.0 & 1162 \\
\hline $8-5$ & 46.8 & 506 & $8-6$ & 17.8 & 1792 \\
\hline $8-7$ & 30.8 & 769 & $8-8$ & 24.3 & 948 \\
\hline $8-9$ & 31.1 & 515 & $8-10$ & 25.8 & 1064 \\
\hline $8-11$ & 38.6 & 626 & $8-12$ & 27.2 & 1364 \\
\hline $8-13$ & 35.9 & 468 & $8-14$ & 30.0 & 1262 \\
\hline $8-18$ & 30.8 & 521 & $8-15$ & 22.2 & 1174 \\
\hline $8-19$ & 47.8 & 337 & $8-16$ & 22.8 & 1088 \\
\hline & & & $8-17$ & 24.5 & 1152 \\
\hline Average & 37.42 & & $8-20$ & 20.3 & 1228 \\
\hline Cov (\%) & 17.71 & 23.35 & Cov (\%) & 13.72 & 20.10 \\
\hline
\end{tabular}

\section{Effect of Inherent Characteristics of Hemp Fibres}

Optical microscope observations showed that considerable deformation occurred in hemp fibres. The results of examination of 1000 hemp test pieces showed that the hemp fibres mainly contain four types of deformation (Dai and Fan 2009), namely a) kink bands, formed in the fibres as a result of axial curing stresses (Fig. 10A); b) nodes, formed in the regions of localized delamination and compressive strain (Fig. 10B); c) dislocations, which appeared in untreated natural fibre (Fig. 10C); and d) slip planes, crinkled in the cell wall resulting from a slight linear displacement of the wall lamellae (Fig. 10D). Under tensile testing, these deformations appear to be the weak points and fail first (Fig. 10E). This may be due partly to the stress concentrations around deformations, which can act as sites for the initiation of fibre matrix debonding as well as for the formation of micro cracks in the matrix. The results are in agreement with the result from a study on inter-phase behaviour of hemp-epoxy composites (Hughes 2000).

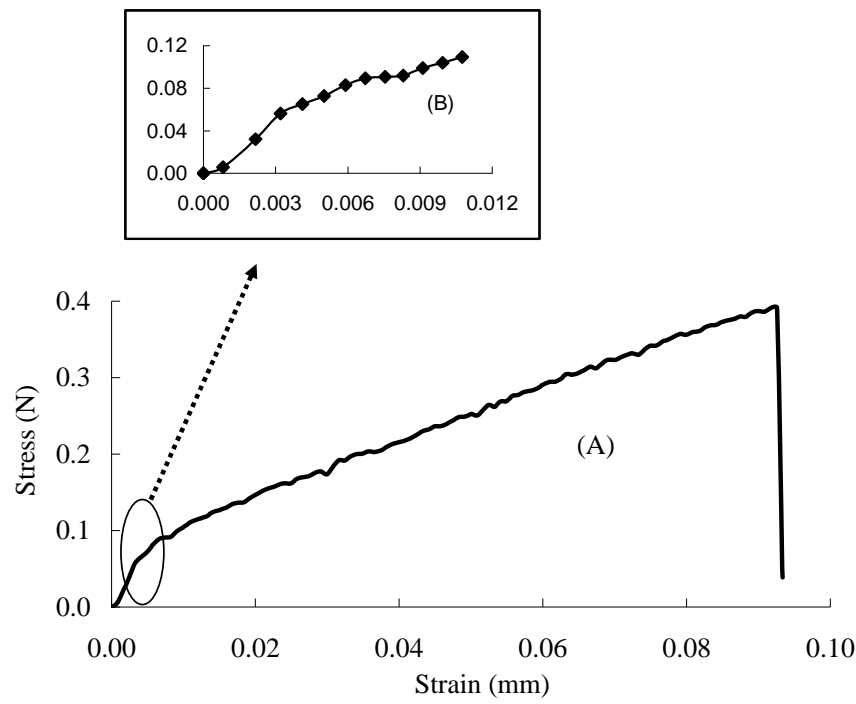

Figure 9. An example of strainstress of single hemp fibre under tensile load 


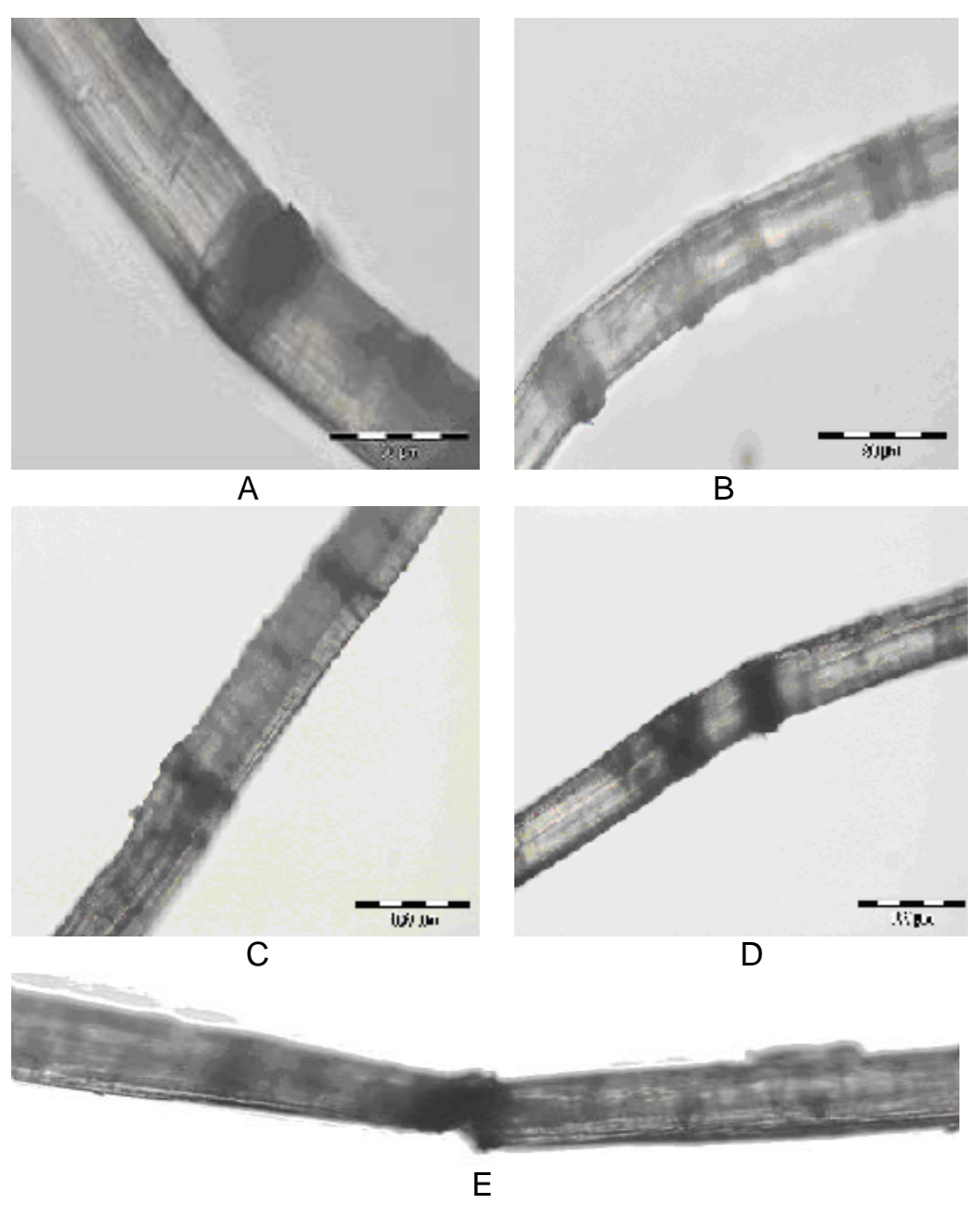

Figure 10. Defects of hemp fibre: $A=k i n k$ band ( $x 500$ magnification), $B=$ node ( $x 500$ magnification), $C=$ dislocation ( $x 200$ magnification), $D=$ slip plane (x200 magnification), $E=$ initial break (x500 magnification)

As mentioned earlier, the test pieces may mostly contain more than one single fibre. These deformations will inevitably complicate the test results. An observation has been carried out to examine the combined effect of the inherent defect and fibre configuration of the test pieces. Figure 11A shows possible configurations of test pieces with single fibres that may contain inherent defects, and Figure 11B shows the corresponding tensile strength of the configured test pieces. More configurations in a group of test pieces are possible, i.e. the test pieces could consist of more defect points or various arrangements between the defects in a test piece. It is very interesting to find that there is a closely relationship between the strength and the fibre configuration within the test pieces. This means that the real tensile strength of single hemp fibre, which does not contain any deformation (inherent joints), may be even higher than that predicted above. The detailed structure and chemical compositions of the regions with and without joints are to be studied, and the results will be published in a separate paper. 


\section{Effect of Processing Defects}

Processing defects should have an influence on the tensile strength of hemp fibres tested. An SEM examination showed that the processed hemp contained splits either along the fibre length or across the fibre diameter or both (Fig. 12). This defect may multiply the effect of test results if the test pieces contain several single fibres (Fig. 13).

\section{Effect of Decortications}

The decorticating processes (including prior treatments) may have significant effect on the quality and strength of hemp fibres, the detailed discussion of which has been presented in a separate report by the author (NATCOM 2009). It was reported that a doubling in strength may be obtained from an improved method of processing, as compared to a normal practice of processing (Fig. 14). The highest tensile strength was $1451 \mathrm{MPa}$ for NATCOM8 (treatment type 8), and the lowest was $787 \mathrm{MPa}$ for NATCOM1 (treatment type 1) (NATCOM 2009).

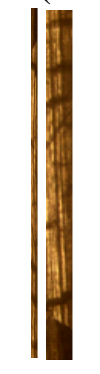

2-Ran

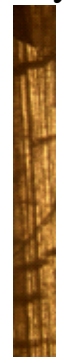

S

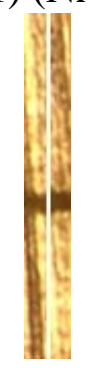

2-R

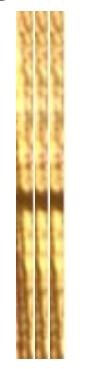

3-R

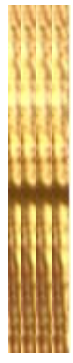

4-R

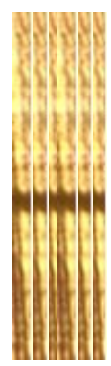

$5-\mathbf{R}$

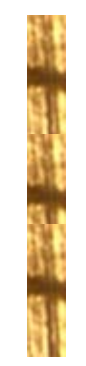

$\mathbf{M}$
A

B

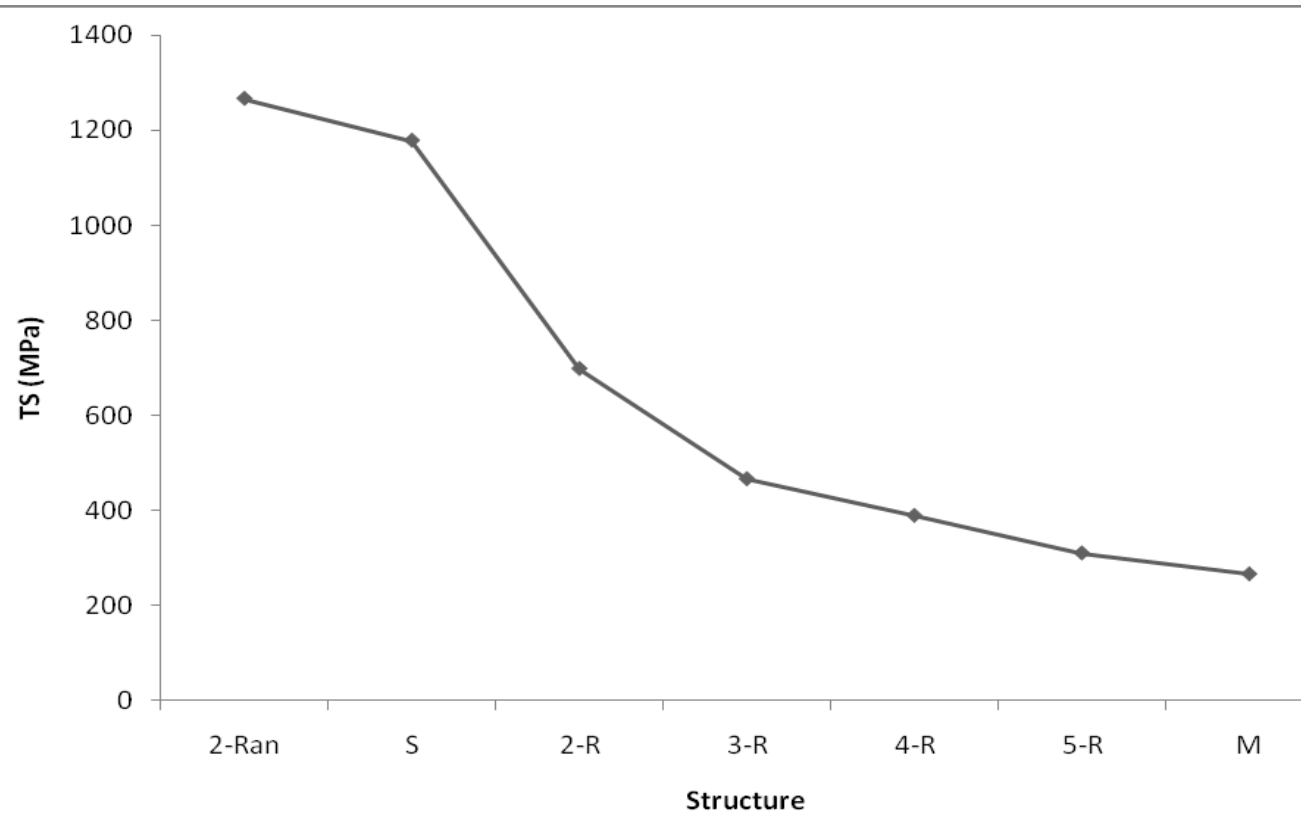

Figure 11. Effect of joints on tensile strength: $A=$ possible configurations of joint/single fibre in a test piece, $B=$ correlation of joint arrangement and tensile strength 


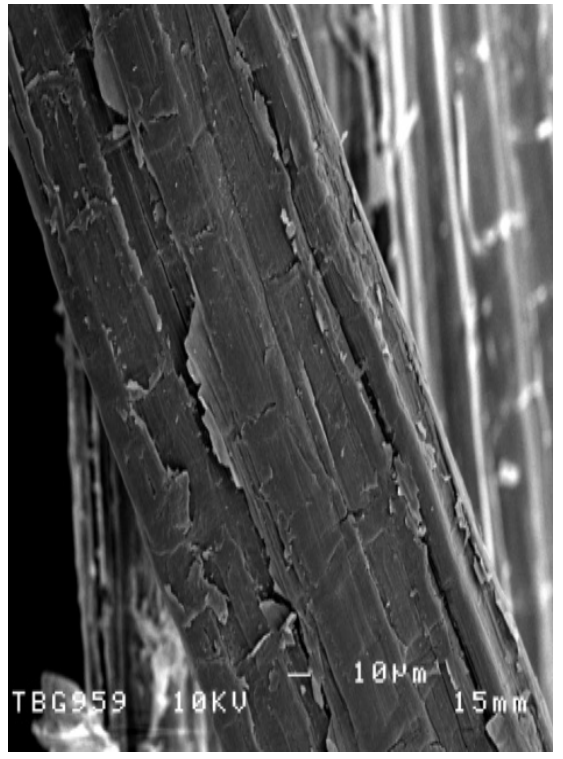

Figure 12. Split/crack of hemp fibres
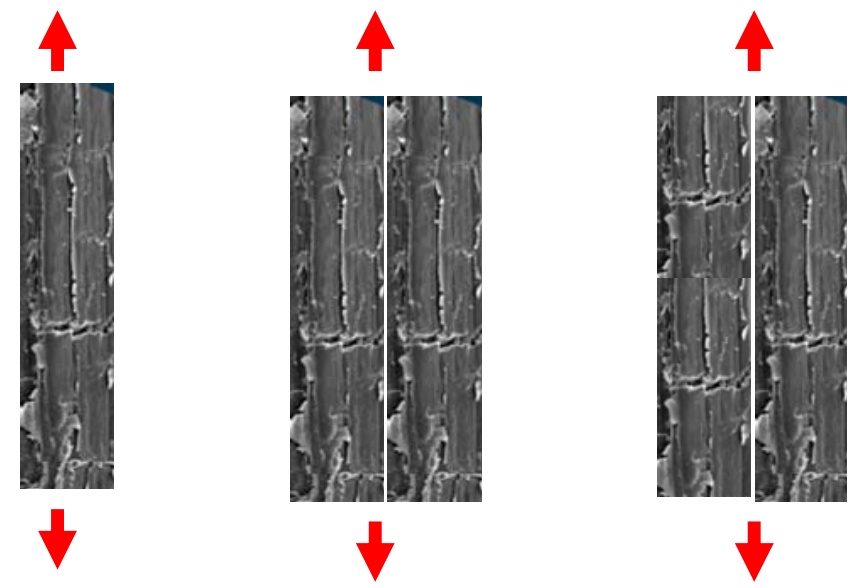

Figure 13. Possible combinations/distribution of splits in a test pieces

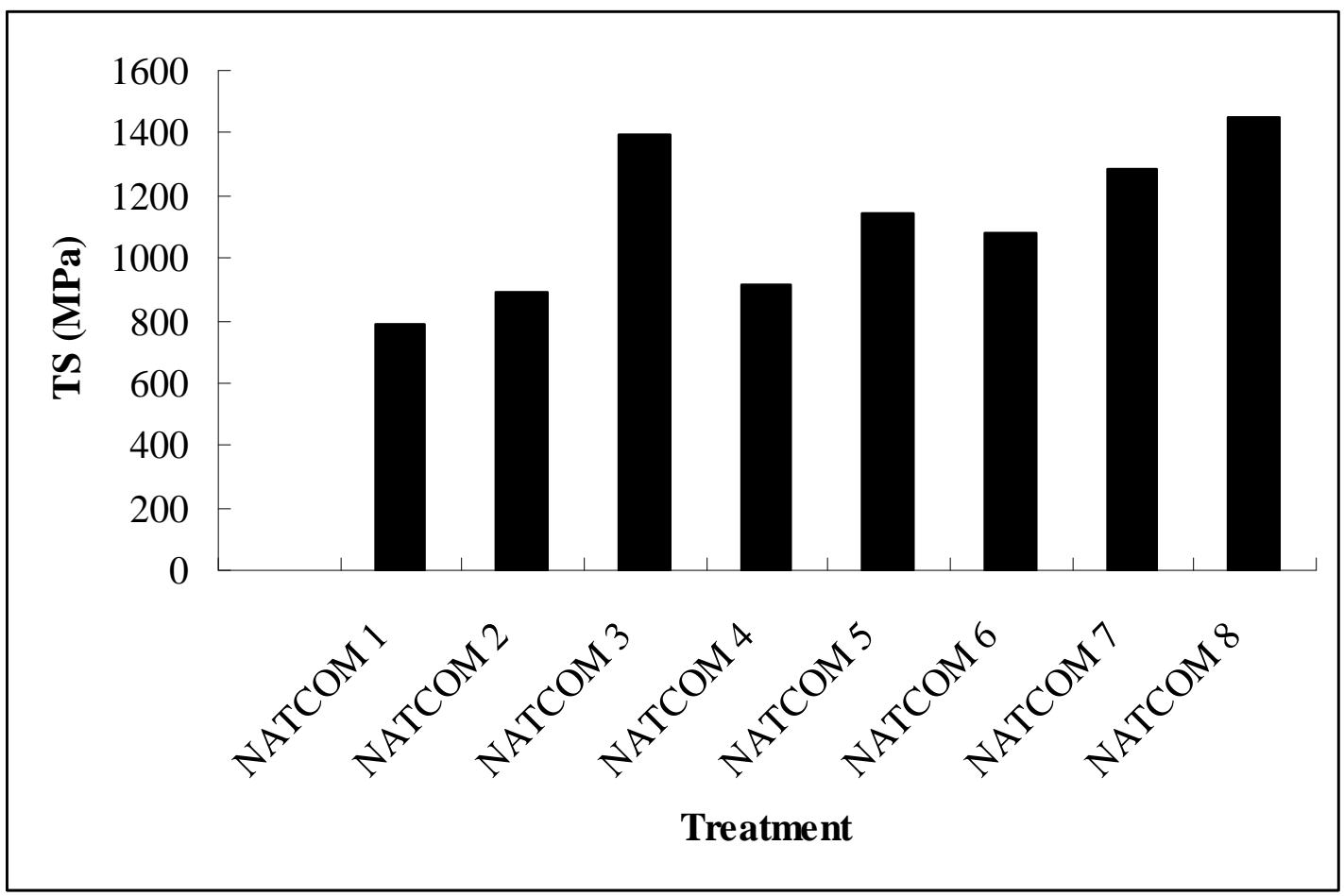

Figure 14. Effect of various treatments on tensile strength 


\section{CONCLUSIONS}

It has been verified that the variable strength data available from the literature may not represent the real strength of single hemp fibres. This data may not be suitable for predicting the performance of hemp fibre composite materials. Numerous factors affecting the strength and tested data of hemp fibres have been investigated, indicating that:

1. the tensile strength increased with a decrease of the diameter of individual test pieces due partly to the stacking of single fibres within the test pieces, leading to a certain percentage of shear failure under tension. The contribution of shear strength could range from 0 to $100 \%$.

2. the tensile strength was closely related to both the number of inherent joints along the fibre length and the number of single fibres contained in a test piece. The strength could range from $250 \mathrm{MPa}$ for the multiple parallel stacking of single fibres to 1250 MPa for the random distribution of joints of a two-fibre combination of test pieces.

3. splits along the length and across the width of hemp fibres, resulting from the processing, complicated the test results.

4. the treatments prior to the decortications had a significant effect on the quality of hemp fibres, with the highest strength doubling that of fibres from a normal retting processing.

A reliable tensile strength of single fibres has been developed by the prediction from the numerous tested data, together with the diameter from the SEM examination of hemp fibres. That is, the diameter of a single hemp fibres ranged between $10-15 \mu \mathrm{m}$, and the strength of a single hemp fibre ranged from $1695 \mathrm{MPa}$ (using 15 $\mu \mathrm{m}$ diameter) to 2767 MPa (using $10 \mu \mathrm{m}$ diameter). The predicted strength was verified by testing carefully prepared test pieces with the average tensile strength tested being $1256 \mathrm{MPa}$ for the test pieces with a diameter $<30 \mu \mathrm{m}$ and $529 \mathrm{MPa}$ with a diameter between 30 and $50 \mu \mathrm{m}$ is $529 \mathrm{MPa}$.

The correlation between strain and stress for these carefully prepared hemp test pieces was found to be linear for all the test pieces, showing that the behaviour of single hemp fibres obeyed Hooke's law.

\section{ACKNOWLEDGMENTS}

The author is grateful for the support of the Technology Strategy Board, United Kingdom. Government Grant No.TP/5/CON/6/I/H0565L

\section{REFERENCES CITED}

Anderson, J., Jansz, A., Steele, K., and Thistlethwaite, P. (2004). Green Guide to Composites. BRE Bookshop, Watford, UK.

Beckermann, G. (2007). Performance of Hemp-Fibre Reinforced Polypropylene Composite Materials. Waikato University, Australia. 
Bhuwan M., Mohini, P., and Sain, M. (2003). "Mechanical properties of thermally treated hemp fibres in inert atmosphere for potential composite reinforcement,” Material Research Innovation 7(4), 231-238.

Bos, H. L., and Donald, A. M. (1999). "In situ ESEM study of the deformation of elementary flax fibres,” J. Materials Science 34, 3029-3034.

Candilo, M., Ranalli, P., and Bozzi, C. (2000). "Preliminary results of tests facing with the controlled retting of hemp,” Industrial Crops and Products 11, 197-203.

Charlet, K., Eve, S., Jernot, J. P., Gomina, M., and Breard, J. (2009) “Deformation of a flax fibre,” Procedia Engineering 1(1), 233-236.

Dai, D., and Fan, M. (2009). "Characteristic and performance of elementary hemp fibre," Proc. Conf. Single-Fibre Testing and Modelling. Stockholm, Sweden. November 4-5.

Davies, G., and Bruce, D. (1998). "Effect of environmental relative humidity and damage on the tensile properties of flax and nettle fibres,” Textile Research Journal 68(9), 623-629.

Eichhorn, S. J., Baillie, C. A., Zafeiropoulos, N., Mwaikambo, L. Y., Ansell, M. P., Dufresne, A., Entwistle, K. M., Herrera-Franco, P. J., Escamilla, G. C., Groom, L., Hughes, M., Hill, C., Rials, T. G., and Wild, P. M. (2001). "Review: Current international research into cellulosic fibres and composites,” Journal of Materials Science 36(9), 2107-2131.

Fan, M., Dai, D., and Yang, A. (2010). "High strength natural fibre composite for construction: Defibrillation and its mechanisms of nano cellulose hemp fibres," ASCE Journal of Materials in Civil Engineering. In press.

Fan, M. (2009). "Research on strong natural fibre composites for construction,” Proc. Conf. 'Natural Fibres in Construction - Innovative Applications and Processes' Cambridge, UK.

Hamad, W.Y., and Eichhorn, S. J. (1997). "Deformation micromechanics of cellulose fibres,” ASME J. Engineering Material and Technology 119, 309-313.

Hearle, J. W. S. (1963). "The fine structure of fibres and crystalline polymers. III. Interpretation of the mechanical properties of fibres,” J. Applied Polymer. Science 7, 1207-1223.

Hughes, M., Hill, C. A. S., Sebe, G., Hague, J., Spear, M., and Mott, L. (2000). “An investigation into the effects of microcompressive defects on interphase behaviour in hemp-epoxy composites using half fringe photoelasticity,” Composite Interfaces 7(1), 13-29.

Mwaikambo, L. Y., and Ansell, M. P. (2006). "Mechanical properties of alkali treated natural fibres and their potential as reinforcement materials: Sisal fibres," Journal of Materials Science 41(8), 2497-2508.

NATCOM. (2009). “Optimally efficient production of natural fibre composites for construction,” Mid-term Project Report for UK government Technology Strategy Board. Brunel University, UK.

Nishino, T. (2004). “Natural fibre resources,” in Green Composites, C. Baillie (ed.), Woodhead Publishing Limited, England.

Panthapulakkal, M. S. (2007). "Injection molded short hemp fibre/ glass fibre-reinforced polypropylene hybrid composites - Mechanical water absorption and thermal properties,” Journal of Applied Polymer Science 103, 2432-2441. 
Purz, H. J., Fink, H. P., and Graf, H. (1998). “The structure of natural cellulosic fibres. Part I: The structure of bast fibres and their changes by scouring and mercerization as revealed by optical and electron microscopy,” Das Papier 6(52), 315-324.

Roulac, J. W. (1997) Hemp Horizons: The Comeback of the World's Most Promising Plant. Chelsea Green Publishing Co.White River Junction.

Satyanarayana, K. G. Arizaga, G. G. C., and Wypych, F. (2009). “Biodegradable composites based on lignocellulosic fibres, an overview," Progress in Polymer Science 34(9), 982-1021.

Stafford, P. (1992). Psychedelics Encyclopedia. Berkeley, California, Ronin Publishing, Inc.

Thygesen, L. G., Bilde-Sørensen, J. B., and Hoffmeyer, P. (2006). "Visualisation of dislocations in hemp fibres A comparison between scanning electron microscopy (SEM) and polarized light microscopy (PLM),” Industrial Crops and Products 24, 181-185.

Wambua, P., Ivens, J., and Verpoest, I. (2003). "Natural fibres: Can they replace glass in fibre reinforced plastics?” Composites Science and Technology 67, 1259-1264.

Xue, Y., Du, Y., Elder, S., Wang, K., and Zhang, J. (2009). “Temperature and loading rate effects on tensile properties of kenaf bast fiber bundles and composites," Composites Part B 40(3), 189-196.

Hu, W., Ton-That, M. T., Perrin-Sarazin, F., and Denault, J. (2010). “An improved method for single fiber tensile test of natural fibers,” Polymer Engineering and Science 50(4), 819-825.

Article submitted: July 25, 2010; Peer review completed: Sept. 1, 2010; Revised version received and accepted: September 11, 2010; Published: September 14, 2010. 